\title{
LOYALITAS WISATAWAN DAMPAK KEPUASAN WISATAWAN, PROMOSI DAN SADAR WISATA MASYARAKAT PULAU TIDUNG
}

\author{
Dian Riskarini ${ }^{1}$, Yuli Ardianto ${ }^{2}$, Reffy $^{3}$ \\ ${ }^{1,2,3}$ Universitas Pancasila, dianriskarini@ univpancasila.ac.id
}

\begin{abstract}
ABSTRAK
Pulau Tidung merupakan salah satu pulau di Kepulauan Seribu sebagai obyek wisata bagi para pengunjung untuk menikmati panorama, wisata air serta karang bawah laut. Masyarakat lokal memanfaatkan peluang ini untuk dikelola secara mandiri sebagai upaya mendukung potensi wisata di daerahnya. Penelitian ini bertujuan untuk menganalisis loyalitas wisatawan yang berkunjung ke Pulau Tidung akibat pengaruh kepuasan wisatawan yang didukung oleh variabel promosi dan sadar wisata masyarakat . Data yang digunakan dalam penelitian ini adalah data primer dengan kuesioner. Jumlah sampel penelitian sebesar 200 responden dengan menggunakan metode deskriptif kuantitatif purposive sampling. Teknik analisis data menggunakan analisis jalur. Hasil penelitian menunjukkan bahwa variabel promosi dan sadar wisata masyarakat memiliki pengaruh positif dan signifikan terhadap kepuasan wisatawan. Kepuasan wisatawan berpengaruh positif dan signifikan terhadap loyalitas wisatawan. Variabel promosi dan sadar wisata masyarakat berpengaruh signifikan dan positif terhadap loyalitas wisatawan. Implikasi dari penelitian ini diharapkan meningkatkan potensi dan promosi wisata di Pulau Tidung didukung oleh pemerintah Kabupaten Kepulauan Seribu dan kesadaran masyarakat lokal sehingga wisatawan berkeinginan Kembali mengunjungi Pulau Tidung.
\end{abstract}

Kata Kunci : promosi, sadar wisaya masyarakat, kepuasan wisatawan, loyalitas wisatawan

\begin{abstract}
Tidung Island is one of the islands in the Thousand Islands as a tourist attraction for visitors to enjoy panoramic views, water tourism and underwater reefs. Local people take advantage of this opportunity to be managed independently in an effort to support the tourism potential in their area. This study aims to analyze the loyalty of tourists visiting Tidung Island due to the influence of tourist satisfaction which is supported by promotional variables and awareness of community tourism. The data used in this study are primary data with a questionnaire. The number of research samples of 200 respondents using quantitative descriptive purposive sampling method. The data analysis technique used path analysis. The results showed that the variable promotion and awareness of community tourism had a positive and significant effect on tourist satisfaction. Tourist satisfaction has a positive and significant effect on tourist loyalty. Promotion variables and awareness of community tourism have a significant and positive effect on tourist loyalty. The implications of this research are expected to increase the potential and promotion of tourism on Tidung Island, supported by the Thousand Islands Regency government and the awareness of the local community so that tourists wish to return to visit Tidung Island..
\end{abstract}

Keywords: promotion, awareness of community tourism, tourist satisfaction, tourist loyalty

Naskah diterima : 22-02-2021 Naskah dipublikasikan: 31-03-2021 


\section{PENDAHULUAN}

Indonesia memiliki ribuan kepulauan yang mempesona, membentang dari wilayah Timur hingga Barat. Telah banyak pesona wisata kepulauan yang diakui baik secara nasional maupun global. Yang terdekat berada di wilayah DKI Jakarta salah satunya adalah Kepulauan Seribu. Jejeran pulau baik yang berpenghuni maupun tidak dengan potensi wisata yang besar dan perlu diangkat ke permukaan agar lebih menarik wisatawan. 11 Pulau dari 110 pulau yang tersebar di wilayah kepulauan Seribu dihuni oleh penduduk lokal yang termasuk sebagai masyarakat Kabupaten Kepulauan Seribu. Sementara sisanya merupakan pulau-pulau kosong tak berpenghuni namun memiliki wisata alam dan bahari yang memukau untuk dijelajahi dan didatangi sebagai daerah wisata nan elok. Selain itu pulau-pulau kosong tersebut juga dijadikan sebagai cagar alam dan cagar budaya

Pulau Tidung sebagai salah satu wilayah yang berpenduduk cukup banyak serta sebagai pulau terbesar dalam gugusan pulau-pulau yang ada di pada wilayah Kelurahan Pulau Tidung dengan luas kurang lebih 50,13 hektar dan memiliki jumlah penduduk sekitar 4.700 jiwa . Berikut ini adalah jumlah kunjungan para wisatawan selama kurun waktu 2016-2019 ke Pulau Tidung :

Tabel 1. Data Kunjungan Wisatawan Pulau Tidung Tahun 2016 - 2019

\begin{tabular}{|c|c|c|}
\hline No. & Tahun & Jumlah Wisatawan \\
\hline 1 & 2016 & 165.391 \\
\hline 2 & 2017 & 149.725 \\
\hline 3 & 2018 & 149.783 \\
\hline 4 & 2019 & 10.356 \\
\hline \multicolumn{2}{|c|}{ Jumlah } & 475.255 \\
\hline
\end{tabular}

Sumber: Data Kelurahan Pulau Tidung Kecamatan Kepulauan Seribu Selatan

Total kunjungan wisatawan ke Pulau Tidung selama periode tahun 2016-2019 berjumlah 475.255 orang wisatawan (Tabel 1). Perlu adanya pengelolaan yang tepat dikarenakan adanya fluktuasi jumlah kunjungan dan juga meningkatnya jumlah kepadatan penduduk di Pulau Tidung. Hal ini perlu dilakukan agar kegiatan pariwisata di Pulau Tidung dapat berkelanjutan. Pengelolaan tersebut menurut Arikunto (2010) dilakukan terhadap beragam aspek yang mendukung kegiatan wisata seperti sarana prasarana,usaha restoran, atraksi wisata dan yang tidak kalah penting adalah pengelolaan lingkungan serta sumber daya manusia.

Yang mendasari observasi saat penelitian ini dilakukan pada wilayah Pulau Tidung adalah diidentifikasinya beberapa permasalahan yang berkaitan dengan :

a. Minat berwisata yang masih rendah, dikarenakan pemikiran wisatawan untuk berkunjung ke Pulau Tidung masih belum maksimal dibandingakan keinginan mereka untuk berwisata ke destinasi wisata yang sudah lebih terkenal dan terpublikasi secara Global.

b. Kurangnya giat promosi akibat masih minimnya kesadaran masyarakat atas potensi daerah dan masyarakatnya. Hal ini perlu untuk dimaksimalkan.

c. Kepuasan wisatawan yang kurang maksimal setelah berkunjung ke Pulau Tidung

d. Sarana dan Prasarana yang terasa masih belum maksimal untuk menunjang kemajuan pariwisata dan kenyamanan para wisatawan.

Berdasarkan uraian diatas, maka penelitian dilakukan untuk memahami apa yang diharapkan oleh wisatawan sebagai upaya pihak terkait terhadap pariwisata di Pulau Tidung sehingga dapat meningkatkan jumlah kedatangan wisatawan. Atas dasar alasan tersebut maka tujuan penelitian ini adalah ingin mengetahui dan menganalisisi lebih spesifik baik secara 
lngsung maupun tidak langsung pengaruh promosi, sadar wisata masyarakat terhadap kepuasan wisatawan dan dampaknya terhadap loyalitas wisatawan pada objek penelitian di Pulau Tidung.

\section{KAJIAN LITERATUR Promosi}

Salah satu yang menunjang keberhasilan penjualan produk maupun jasa adalah promosi. Hal ini dilakukan untuk memperkenalkan produk/jasa kepada masyarakat luas agar kesadaran mereka lebih meningkat. Promosi juga digunakan untuk menginformasikan manfaat dari suatu produk. Pengertian promosi menurut Hermawan (2012: 38) adalah salah satu komponen prioritas dari kegiatan pemasaran yang memberitahukan kepada konsumen bahwa perusahaan meluncurkan produk baru yang menggoda konsumen untuk melakukan kegiatan pembelian. Promosi merupakan kegiatan terakhir dari marketing mix yang sangat penting karena kebanyakan pasar lebih banyak bersifat pasar pembeli dimana keputusan terakhir terjadinya transaksi jual beli sangat dipengaruhi oleh konsumen (Daryanto, 2011).

Menurut Kotler dalam Sri Rahayu (2019: 29), mengklasifikasi alat pemasaran menjadi empat kelompok yang unsur layanannya rendah yang disebut $4 \mathrm{P}$, yaitu: produk (product), harga (price), tempat (place), dan promosi (promotion). Pada Pemasaran yang unsur layanannya tinggi maka unsur layanan 4P ditambahkan menjadi 7P, yaitu People, Physical Evidence, dan Process. Menurut Kotler dan Keller (2012: 478) Terdapat 8 cara komunikasi utama pada bauran pemasaran , antara lain Advertising (periklanan), Sales Promotion (promosi penjualan), Event and experiences (acara dan pengalaman), Public relations and publicity (hubungan masyarakat dan publisitas), Direct marketing (penjualan langsung), Interactive marketing (pemasaran interaktif), Word of mouth (dari mulut ke mulut), Personal selling (penjualan perorangan).

\section{Sadar Wisata Masyarakat}

Pemahaman mendalam serta kesadaran pemikiran yang terwujud melalui sikap dan tingkah laku sebagai tuan rumah yang baik dari individu ataupun kelompok masyarakat mampu mendukung pengembangan pariwisata di wilayahnya. Hal inilah yang disebut sebagai Sadar Wisata. Kesadaran wisata ini dapat berbentuk kesadaran masyarakat dalam ikut berperan melakukan dua hal berikut ini (Rahim, 2015) :

a. Turut serta mewujudkan suasana kondusif dengan menyadari peran dan tanggung jawabnya sebagai tuan rumah yang baik bagi wisatawan yang berkunjung.

b. Menyadari hak, kebutuhan dan kewajiban sebagai pelaku wisata yang sedang melakukan perjalanan wisata maupun mengenal dan menjaga daerah wisata yang dikunjungi.

Sadar wisata merupakan bentuk partisipasi dan dukungan segenap komponen masyarakat untuk berkembangnya kepariwisataan di suatu daerah (Hariyanto, 2017).Unsurunsur yang harus dipahami dan diwujudkan oleh masyarakat adalah Aman, Tertib, Bersih, Sejuk, Indah, Ramah dan Kenangan (Sapta Pesona). Dengan berkembangnya potensi kepariwisataan diharapkan mampu meningkatkan pertumbuhan ekonomi dan kesejahteraan masyarakat lokal, mempercepat pertumbuhan ekonomi dengan pemerataan hasil-hasil pembangunan sehingga kesenjangan yang ada mampu teratasi.

\section{Kepuasan Pelanggan}

Penilaian tentang kekhasan atas ciri suatu produk atau jasa yang menyediakan tingkat kesenangan dan pemenuhan kebutuhan konsumsi konsumen adalah makna suatu kepuasan. Kepuasan dapat diciptakan melalui kualitas produk/jasa, pelayanan prima dan nilai yang dirasakan konsumen. Pengalaman yang diperoleh seseorang dapat memutuskan suatu sikap kepuasan seseorang (Lovelock dan Wirtz, 2011).

Respon pelanggan terhadap evaluasi persepsi atas perbedaan harapan awal ( standar kinerja lainnya) dan kinerja actual produk/jasa setelah digunakan atau dikonsumsi pelanggan 
menimbulkan suatu bentuk kepuasan (Tjiptono, 2012). Hal ini berarti kepuasan bukanlah hal yang bersifat absolut namun relative tergantung pada apa yang diharapkan seseorang. Karena kepuasan pelanggan bergantung pada persepsi dan ekspektasinya, maka menurut Fandy Tjiptono (2016) terdapat lima factor yang bisa mempengaruhi kepuasan pelanggan yaitu :

a. Produk/Jasa yang berkualitas .

b. Penetapan harga yang relative murah dengan kualitas yang baik akan menambah nilai suatu produk/jasa.

c. Pemberian pelayanan berkualitas sesuai harapan pelanggan.

d. Faktor Emosional yang terjaga menyebabkan suatu nilai fanatisme atas suatu produk/jasa dengan merek tertentu .

e. Kemudahan atas proses mendapatkan produk/jasa, efisiensi biaya dan waktu.

\section{Loyalitas Pelanggan}

Komitmen mendalam untuk membeli dan mempergunakan Kembali produk dan jasa secara konsisten dimasa yang akan datang sehingga mendorong niat pembelian merek yang sama walaupun terdapat pengaruh situasional dan usaha pemasaran lain adalah definisi Loyalitas menurut Wantara (2015). Hal yang sama juga disampaikan oleh Ikbal (2015), loyalitas pelanggan ditandai adanya keterikatan yang era tantara pelaku bisnis dengan para pelanggannya sehingga timbul keinginan melakukan pembelian berulang atas dasar komukasi yang positif diantara kedua belah pihak tersebut.

Sedangkan definisi lainnya tentang loyalitas pelanggan disampaikan oleh Wiranto (2015) yaitu sebagai pola pikir dan sikap pelanggan yang menguntungkan perusahaan seperti berkomitmen menggunakan kembali layanan dan produk serta merekomendasikan kepada orang lain. Ranto (2014) menyatakan pentingnya mempertahankan tingkat kepuasan pelanggan dengan meningkatkan nilai kepuasannya, hal ini mampu menciptakan konsumen yang loyal dan memiliki hubungan jangka Panjang.

Griffin dalam Ratih Hurriayanti (2010) menyatakan bahwa pelanggan yang loyal memiliki karakteristik yang juga merupakan dimensi loyalitas sebagai berikut:

a. Melakukan pembelian berulang secara teratur atau berkunjung kembali.

b. Pembelian lintas lini produk dan layanan

c. Mengacu orang lain atau merekomendasikan produk/jasa kepada orang lain.

d. Menunjukan kekebalan terhadap tarikan kompetisi dengan tidak mudah terpengaruh pihak pesaing.

Berikut adalah gambar kerangka pemikiran dalam penelitian ini :

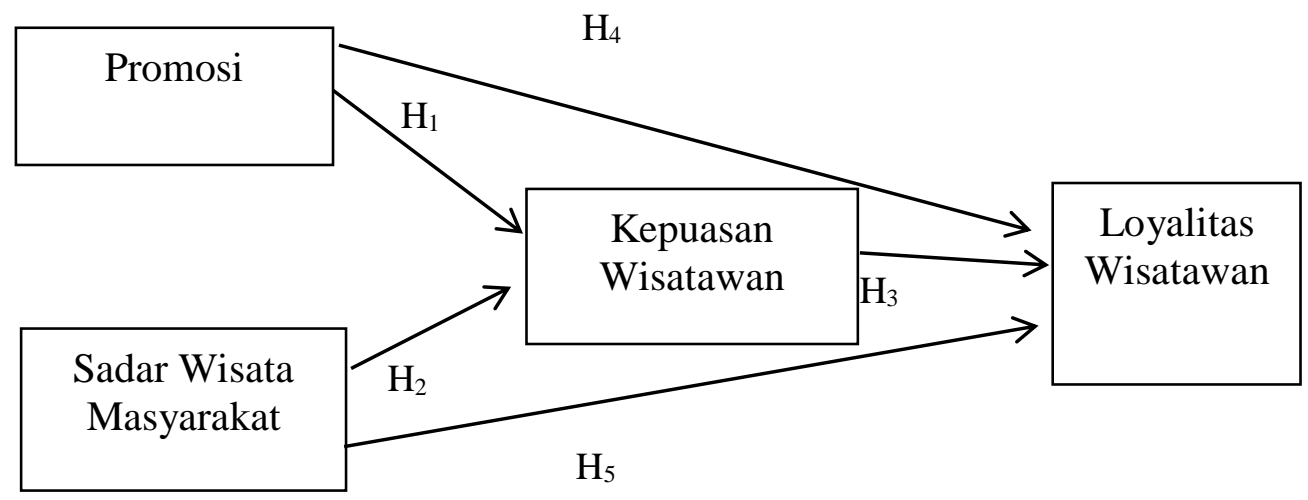

Gambar 1. Kerangka Pemikiran Penelitian 
Beberapa hipotesis penelitian yang harus dibuktikan secara analisis berdasarkan framework diatas adalah :

$\mathrm{H}_{1}$ : promosi berpengaruh terhadap kepuasan wisatawan

$\mathrm{H}_{2}$ : sadar wisata masyarakat berpengaruh terhadap kepuasan wisatawan

$\mathrm{H}_{3}$ : kepuasan wisatawan berpengaruh terhadap loyalitas wisatawan

$\mathrm{H}_{4}$ : promosi berpengaruh terhadap loyalitas wisatawan

$\mathrm{H}_{5}$ : sadar wisata masyarakat berpengaruh terhadap loyalitas wisatawan

$\mathrm{H}_{6}$ : promosi berpengaruh melalui kepuasan wisatawan terhadap loyalitas wisatawan

$\mathrm{H}_{7}$ : sadar wisata masyarakat berpengaruh melalui kepuasan wisatawan terhadap loyalitas wisatawan

\section{METODE PENELITIAN}

Metode penelitian yang digunakan adalah metode deskriptif verifikatif. Metode deskriptif pada penelitian ini digunakan untuk menganalisis pengaruh promosi dan sadar wisata masyarakat terhadap kepuasan dan loyalitas pelanggan pada obyek wisata Pulau Tidung. Metode penelitian verifikatif (Sugiyono, 2013) adalah suatu metode yang bertujuan mengetahui hubungan antara dua variabel atau lebih yang diajukan dalam hipotesis. Pendekatan penelitian yang digunakan adalah pendekatan kuantitatif dengan 200 sampel responden.

Teknik sampling yang digunakan dalam penelitian adalah nonprobability, sedangkan metode yang digunakan adalah purposive sampling yaitu teknik penentuan sampel dengan pertimbangan tertentu (Sugiyono, 2012). Dalam hal ini pengumpulan data dilakukan melalui wisatawan yang sudah melakukan kunjungan lebih dari sekali di wisata Pulau Tidung dan masyarakat Pulau Tidung yang memiliki usaha maupun berperan serta dalam pariwisata lokal. Teknik analisis data dalam penelitian ini mengelola path analysis. Model ini bertujuan mengetahui adanya pengaruh baik secara langsung maupun tidak langsung dari seperangkat variable eksogen terhadap variable endogen (Kuncoro, 2010) .

Metode Deskriptif untuk memberikan gambaran akurat sebuah data dan Hipotesis Testing untuk menguji hipotesis tertentu yang menjelaskan hubungan antar dua atau lebih dalam variabel penelitian. Desain penelitian menggunakan pendekatan Survey dan Design Cross Sectional. Alat analisis data yang digunakan adalah SEM (structural Equation Modeling), yang dioperasikan melalui program AMOS 16.0. Teknik estimasi dilakukan dengan dua tahap, yaitu Estimasi Meansurement Model digunakan untuk menguji undimensionalitas dari konstrukkonstruk eksogen dan edogen dengan menggunakan Teknik Confirmatory Factor Analysis dan tahap Estimasi Structural Equation Model dilakukan melalui full model untuk melihat kesesuain model dan hubungan kualitas yang dibuang dalam model ini. Kesesuaian model melalui telaah terhadap berbagai kriteria Goodness-of-fit .

\section{PEMBAHASAN}

Potensi sumber daya alam bahari dan pesisir di Kepulauan Seribu perlu dikelola secara professional dan dipublikasikan lebih luas kepada khalayak ramai. Sebagai destinasi pariwisata berbasis masyarakat maka beragam kekayaan alam dan bahari di kepualauan ini perlu tetap terjaga kelestariannya. Peluang industri pariwisata di wilayah ini akan turut meningkatkan kesejahteraan masyarakat penduduk lokal selain tetap dijaga sebagai cagar alam kekayaan bangsa. Salah satu lokasi wisata nan elok itu terletak di Pulau Tidung, salah satu pulau berpenduduk terbesar di Kecamatan Kepulauan Seribu Selatan.

Berdasarkan data primer (kuesioner) yang telah diperoleh, maka dilakukan analisis berdasarkan karakteristik responden. Responden penelitian ini adalah masyarakat lokal dan wisatawan yang berkunjung ke destinasi Pulau Tidung. Berikut ini dijelaskan profil tentang 
responden yang meliputi jenis kelamin. Berdasarkan jenis kelamin, jumlah yang paling banyak adalah berjenis kelamin wanita sebanyak 145 orang dan sisanya berjenis kelamin pria sebanyak 55 orang. Berdasarkan jenis usia yang datang berkunjung ke destinasi Pulau Tidung dan masyarakat lokal sifatnya beragam namun yang paling banyak adalah responden yang berusia produktif antara 18 - 25 tahun sejumlah 70 orang atau 35\%. Berdasarkan Pendidikan yang telah dijalani seseorang tentulah tidak sama antara individu satu dengan lainnya sehingga menanamkan sebuah pola fikir yang berbeda pula. Hal ini dapat mempengaruhi perilaku seseorang dalam melakukan keputusan dalam berkunjung. Diketahui bahwa pendidikan terakhir responden pada jenjang SD adalah 20 orang (10\%), kemudian pada jenjang SLTP terdapat 40 orang $(20 \%)$, dan pada jenjang SMA yaitu 60 0rang (30\%). Sedangkan pada jenjang sarjana terdapat 80 orang atau $40 \%$. Hal tersebut dikarenakan kebanyakan dari para responden yang berkunjung ke Pulau Tidung adalah para pekerja yang memiliki jenjang pendidikan terakhir sarjana.

\section{Hasil Penelitian}

Hasil penelitian diawali dengan tahapan pengujian kelayakan model yang melalui dua tahap yaitu pengujian measurement dan structural model . Pengujian GOF dilakukan untuk menguji seberapa fit model dengan data-data penelitian yang diperoleh. Gambar 2 adalah gambar path diagram yang telah dilakukan perhitungan dengan AMOS 23.

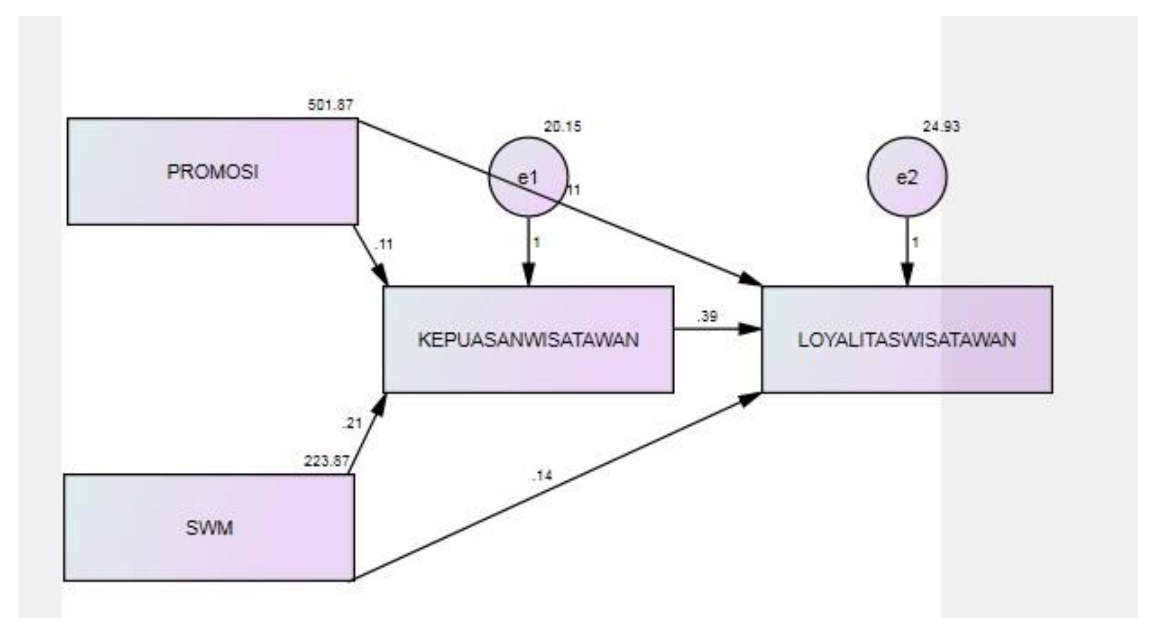

Gambar 2. Path Diagram Dengan AMOS

Sumber : hasil pengolahan data menggunakan AMOS 23

Berdasarkan model tersebut dibuat rangkuman perhitungan uji reliabilitas dan hasil pengujian GOF yang dapat dilihat pada tabel 2 sebagai berikut :

Tabel 2. Hasil Uji Goodness of fit

\begin{tabular}{|c|c|c|c|c|}
\hline No & $\begin{array}{c}\text { Goodness of Fit (GOF) } \\
\text { index }\end{array}$ & $\begin{array}{c}\text { Cut - Off Value } \\
\text { (Nilai Batas) }\end{array}$ & $\begin{array}{c}\text { Nilai pada } \\
\text { model (Hasil) }\end{array}$ & Keterangan \\
\hline 1 & Chi Square $\left(\mathrm{x}^{2}\right)$ & $\begin{array}{c}\text { Semakin kecil semakin baik } \\
(<214,477)\end{array}$ & 224.650 & Closefit \\
\hline 2 & CMIN/DF & $<2,00$ & 224.650 & Closefit \\
\hline 3 & Probability Level & $>0,05$ & 0.000 & Closefit \\
\hline 4 & GFI & GFI $>0,9$ (Good Fit) 0,8 GFI & 0.747 & Marginal \\
\hline
\end{tabular}




\begin{tabular}{|c|c|c|c|c|}
\hline No & $\begin{array}{c}\text { Goodness of Fit (GOF) } \\
\text { index }\end{array}$ & $\begin{array}{c}\text { Cut - Off Value } \\
\text { (Nilai Batas) }\end{array}$ & $\begin{array}{c}\text { Nilai pada } \\
\text { model (Hasil) }\end{array}$ & Keterangan \\
\hline 5 & AGFI & $>0.90$ & -1.533 & Goodfit \\
\hline 6 & TLI & $>0,95$ & $-1,249$ & Goodfit \\
\hline 7 & CFI & $\begin{array}{c}\text { CFI }>0,95 \text { (Good Fit) } \\
0,8 \text { CFI 0,9 } \\
\text { (Marginal Fit) }\end{array}$ & 0.625 & Closefit \\
\hline 8 & $\begin{array}{c}\text { Root Mean Square Error of } \\
\text { Approximation } \\
\text { (RMSEA) }\end{array}$ & $<0.08$ & 1.063 & Goodfit \\
\hline
\end{tabular}

Sumber : hasil pengolahan data menggunakan AMOS 23

Berdasarkan hasil Analisa tabel 2 nilai pengujian GOF dan Chi Square $\left(\mathrm{X}^{2}\right)$ telah memenuhi kriteria GOF. Ukuran-ukuran kelayakan model yang lain berada dalam kategori baik. Nilai Probabilitas yang menunjukkan tidak adanya perbedaan antara model yang diprediksikan dengan data pengamat. Dengan demikian kecocokan model yang diprediksikan dengan nilainilai pengamatan yang diajukan dapat diterima .

Tabel 3. Hasil Uji Hipotesis

\begin{tabular}{|lrl|rrrr|}
\hline & & & Estimate & S.E. & C.R. & P \\
\hline KEPUASAN WISATAWAN & $<---$ & PROMOSI & .106 & .014 & 7.436 & $* * *$ \\
KEPUASAN WISATAWAN & $<--$ & SWM & .213 & .021 & 9.991 & $* * *$ \\
LOYALITAS WISATAWAN & $<---$ & KEPUASAN & .391 & .079 & 4.945 & $* * *$ \\
LOYALITAS WISATAWAN & $<---$ & SWM & .144 & .029 & 4.961 & $* * *$ \\
LOYALITAS WISATAWAN & $<---$ & PROMOSI & .110 & .018 & 6.117 & $* * *$ \\
\hline
\end{tabular}

Sumber : hasil pengolahan data menggunakan AMOS 23

Tabel 4. Standardized Regression Weights: (Group number 1 - Default model)

\begin{tabular}{|ll|r|}
\hline & \multicolumn{1}{|c|}{ PROMOSI } & .396 \\
KEPUASANWISATAWAN & $<--$ SWM & .532 \\
LOYALITASWISATAWAN & $<--$ KEPUASANWISATAWAN & .328 \\
LOYALITASWISATAWAN & $<--$ SWM & .302 \\
LOYALITASWISATAWAN & $<--$ PROMOSI & .344 \\
\hline
\end{tabular}

Sumber : hasil pengolahan data menggunakan AMOS 23

Berdasarkan pada tabel 3 dan 4. bahwa setiap dimensi pembentukan variabel laten menunjukan hasil yang memenuhi kriteria nilai p lebih kecil dari 0.05. jika hasil memenuhi kriteria pada nilai p maka variabel laten tersebut dapat dikatakan signifikan. Dengan demikian model yang dipakai dalam penelitian dapat diterima. 
Tabel 5. Hasil Perhitungan Hipotesis

\begin{tabular}{|c|c|c|c|c|}
\hline Variabel & C.R & P & Kategori & Keterangan \\
\hline Promosi < Kepuasan Wisatawan & 7.436 & $* * *$ & Signifikan & $\begin{array}{c}\text { Ha diterima } \\
\text { Ho ditolak }\end{array}$ \\
\hline SWM < Kepuasan Wisatawan & 9.991 & $* * *$ & Signifikan & $\begin{array}{c}\text { Ha diterima } \\
\text { Ho ditolak }\end{array}$ \\
\hline $\begin{array}{c}\text { Kepuasan Wisatawan < Loyalitas } \\
\text { Wisatawan }\end{array}$ & 4.945 & $* * *$ & Signifikan & $\begin{array}{c}\text { Ha diterima } \\
\text { Ho ditolak }\end{array}$ \\
\hline SWM < Loyalitas Wisatawan & 4.961 & $* * *$ & Signifikan & $\begin{array}{c}\text { Ha diterima } \\
\text { Ho ditolak }\end{array}$ \\
\hline Promosi < Loyalitas Wisatawan & 6.117 & $* * *$ & Signifkan & $\begin{array}{c}\text { Ha diterima } \\
\text { Ho ditolak }\end{array}$ \\
\hline
\end{tabular}

Sumber : Data yang diolah menggunakan AMOS 23

Semua hipotesa diterima karena semua nilai $\mathrm{P}$ adalah Signifikan berarti semua variabel berhubungan dan berpengaruh hasilnya dalam penelitian ini.

\section{a. Pembahasan Pengaruh Langsung dan Tidak Langsung}

Berikut adalah pembahasan pengaruh langsung dan tidak langsung yang ditunjukan untuk melihat seberapa kuat pengaruh suatu variabel dengan variabel lainnya baik secara langsung, maupun secara tidak langsung.

Tabel 6. Pengaruh Langsung

Standardized Direct Effects (Group number 1 - Default model)

\begin{tabular}{|l|rrr|}
\hline & SWM & PROMOSI & $\begin{array}{r}\text { KEPUASAN } \\
\text { WISATAWAN }\end{array}$ \\
\hline KEPUASANWISATAWAN & .532 & .396 & .000 \\
LOYALITASWISATAWAN & .302 & .344 & .328 \\
\hline
\end{tabular}

Sumber : Hasil data yang diolah menggunakan AMOS 23

Berdasarkan hasil perhitungan pada Tabel 6, pengaruh Promosi dan Sadar wisata masyarakat terhadap Kepuasan wisatawan dapat disimpulkan memiliki pengaruh langsung untuk sadar wisata, sebesar 0.532 dan promosi sebesar 0,396. Terlihat variabel sadar wisata memiliki pengaruh lebih besar terhadap kepuasan wisatawan (sebesar 0.532). Dan pengaruh langsung promosi dan sadar wisata masyarakat terhadap loyalitas wisatawan dapat disimpulkan bahwa sadar wisata masyarakat memiliki pengaruh langsung sebesar 0.302 dan Promosi berpengaruh langsung 0.344. Variabel Promosi memiliki pengaruh langsung lebih besar terhadap Loyalitas wisatawan (sebesar 0.344).

Tabel 7. Pengaruh Tidak Langsung

Standardized Indirect Effects (Group number 1 - Default model)

\begin{tabular}{|l|rrr|}
\hline & SWM & PROMOSI & KEPUASAN WISATAWAN \\
\hline KEPUASANWISATAWAN & .000 & .000 & .000 \\
LOYALITASWISATAWA & .174 & .130 & .000 \\
$\mathrm{~N}$ & .174 & \\
\hline
\end{tabular}

Sumber : Hasil data yang diolah menggunakan AMOS 23

Kemudian pada Tabel 7, hasil perhitungan pengaruh tidak langsung dari promosi dan sadar wisata masyarakat terhadap loyalitas wisatawan dapat dilihat nilai yang lebih besar dari 
sadar wisata masyarakat yang memiliki pengaruh tidak langsung sebesar 0.174 sementara variabel promosi memiliki pengaruh tidak langsung hanya sebesar 0.130 .

Tabel 8. Pengaruh total

Standardized Total Effects (Group number 1 - Default model)

\begin{tabular}{|l|ccr|}
\hline & SWM & PROMOSI & $\begin{array}{r}\text { KEPUASAN } \\
\text { WISATAWAN }\end{array}$ \\
\hline KEPUASANWISATAWAN & .532 & .396 & .000 \\
LOYALITASWISATAWAN & .477 & .473 & .328 \\
\hline
\end{tabular}

Sumber : Hasil data yang diolah menggunakan AMOS 23

Dari Tabel 8, hasil perhitungan pengaruh promosi dan sadar wisata masyarakat terhadap loyalitas wisatawan menunjukan bahwa variabel sadar wisata masyarakat memiliki pengaruh total yang lebih besar (0.477) dari pada pengaruh total dari promosi $(0.473)$. kemudian hasil perhitungan total pengaruh promosi dan sadar wisata masyarakat terhadap kepuasan wisatawan menunjukan bahwa sadar wisata masyarakat memiliki pengaruh total lebih besar yaitu 0.532 daripada loyalitas wisatawan dan promosi sebesar 0.396 .

\section{Pembahasan Hasil Penelitian}

Berdasarkan hasil pengujian secara statistik dapat dilihat dengan jelas bahwa semua variabel bebas berpengaruh terhadap variabel terikat.

\section{Pengaruh promosi terhadap kepuasan wisatawan pada wisata Pulau Tidung}

Promosi berpengaruh positif dan signifikan terhadap loyalitas wisatawan pada wisata Pulau Tidung (CR sebesar $7.436>1,967$ dengan nilai probability sebesar $0.000<0.05(\alpha=5 \%)$ ). Hasil Analisa ini menunjukan bahwa intensitas promosi yang berkualitas perlu dilakukan dan ditingkatkan karena akan mempengaruhi kepuasan wisatawan di Pulau Tidung. Hasil penelitian ini sesuai dengan penelitian yang dilakukan oleh Arsti dan Tari (2017) yang menyatakan ada hubungan positif dan signifikan antara promosi terhadap kepuasan.

\section{Sadar Wisata Masyarakat berpengaruh terhadap Kepuasan Wisatawan pada wisata Pulau Tidung}

Sadar wisata masyarakat berpengaruh positif dan signifikan terhadap Kepuasan Wisatawan pada wisata Pulau Tidung (CR sebesar $4.961>1,967$ dengan nilai probability sebesar $0.000<0.05(\alpha=5 \%))$. Jika kesadaran wisata masyarakat Pulau Tidung semakin baik terhadap potensi wilayah, masyarakat dan sarana prasarananya maka akan semakin besar kepuasan wisatawan yang diperoleh sehingga berdampak pada keinginannya untuk Kembali berkunjung. Hal ini sejalan dengan hasil penelitian terdahulu yang dilakukan Hary Hermawan (2017) bahwa daya Tarik wisata, keselamatan, dan sarana wisata berpengaruh positif dan signifikan terhadap kepuasan pelanggan.

\section{Kepuasan Wisatawan Berpengaruh terhadap Loyalitas Wisatawan pada wisata Pulau Tidung}

Kepuasan wisatawan berpengaruh positif dan signifikan terhadap Loyalitas wisatawan (CR sebesar $4.945>1,967$ dengan nilai probability sebesar $0.000<0.05(\alpha=5 \%)$.). Hasil penelitian menunjukkan semakin baik ekspektasi yang terpenuhi dan dirasakan wisatawan atas pengalamannya berwisata ke Pulau Tidung akan membuat para wisatawan merasa ingin kembali untuk berkunjung dan mengeksploitasi lebih dalam lagi atas potensi wisata di Pulau Tidung. Hal ini perlu menjadi perhatian seluruh pihak agar tetap bisa menjaga kualitas dwstinasi wisata sehingga terus bisa meningkatkan loyalitas wisatawan. Sejalan dengan hasil penelitian 
Hasaruddin (2017) yang menyatakan kepuasan wisatawan berpengaruh positif dan signifikan terhadap loyalitas wisatawan.

\section{Pengaruh Sadar Wisata Masyarakat terhadap Loyalitas Wisatawan pada wisata Pulau Tidung}

Berdasarkan hasil penelitian menunjukan bahwa sadar wisata masyarakat berpengaruh positif dan signifikan terhadap loyalitas wisatawan pada wisata Pulau Tidung (CR sebesar 9.991 $>1,967$ dengan nilai probability sebesar $0.000<0.05(\alpha=5 \%)$ ). Sehingga analisa dari model riset ini menunjukan bahwa kesadaran akan potensi wisata masyarakat yang baik akan mempengaruhi loyalitas wisatawan Pulau Tidung. Hary Hermawan (2017) menyatakan daya tarik wisata, keselamatan, dan sarana wisata berpengaruh positif dan signifikan terhadap loyalitas wisatawan.

\section{Promosi berpengaruh terhadap Loyalitas Wisatawan pada Wisata Pulau Tidung}

Hasil penelitian menunjukan bahwa Promosi berpengaruh positif dan signifikan terhadap Kepuasan Wisatawan pada wisata Pulau Tidung (CR sebesar $6.117>$ 1,967 dengan nilai probability sebesar $0.000<0.05(\alpha=5 \%))$. Sehingga analisa dari model riset ini menunjukan Semakin besar promosi kepada wisatawan terhadap wisata Pulau Tidung maka semakin tinggi pula loyalitas wisatawan yang diperoleh, sebaliknya semakin kecil promosi maka semakin rendah pula loyalitas wisatawan terhadap destinasi wisata Pulau Tidung.

Pengaruh tidak langsung (indirect effect) dan pengaruh total (total effect) promosi terhadap loyalitas wisatawan melalui kepuasan wisatawan

Tabel 9. Indirect Effect dan Total Effect

\begin{tabular}{|l|rrr|}
\hline & SWM & PROMOSI & $\begin{array}{r}\text { KEPUASAN } \\
\text { WISATAWAN }\end{array}$ \\
\hline KEPUASANWISATAWAN & .532 & .396 & .000 \\
LOYALITASWISATAWAN & .477 & .473 & .328 \\
\hline
\end{tabular}

Sumber : Hasil data yang diolah menggunakan AMOS 23

Berdasarkan Tabel 9, besaran pengaruh promosi dan sadar wisata masyarakat terhadap loyalitas wisatawan menujukan bahwa sadar wisata masyarakat memiliki pengaruh total yang paling besar (0.532) dari pada pengaruh total dari promosi (0.396). Padma Triscahyaning Wibawa, Naili Farida, Sari Listyorini, (2014), menyatakan Promosi melalui Kepuasan Pelanggan berpengaruh positif dan signifikan terhadap Loyalitas Pelanggan pengunjung Taman Wisata Bukit Sakura.

Pengaruh tidak langsung (indirect effect) dan pengaruh total (total effect) sadar wisata masyarakat terhadap loyalitas wisatawan melalui kepuasan wisatawan

Tabel 10. Indirect Effect dan Total Effect

\begin{tabular}{|l|rrr|}
\hline & SWM & PROMOSI & $\begin{array}{r}\text { KEPUASAN } \\
\text { WISATAWAN }\end{array}$ \\
\hline KEPUASANWISATAWAN & .532 & .396 & .000 \\
LOYALITASWISATAWAN & .477 & .473 & .328 \\
\hline
\end{tabular}

Sumber : Hasil data yang diolah menggunakan AMOS 23

Berdasarkan Tabel 10, tercermin pengaruh total antar variable terhadap loyalitas wisatawan. Promosi dan sadar wisata masyarakat terhadap loyalitas wisatawan menunjukan 
bahwa sadar wisata masyarakat memiliki pengaruh total lebih besar 0.477 daripada loyalitas wisatawan variabel promosi sebesar 0.473 dan melalui variable kepuasan wisatawan sebesar 0.328. Hary Hermawan (2017), menyatakan daya tarik wisata, keselamatan, dan sarana wisata melalui Kepuasan pelanggan berpengaruh positif dan signifikan terhadap loyalitas wisatawan.

\section{PENUTUP \\ Simpulan}

Berdasarkan uraian yang telah dikemukakan pada pembahasan maka dapat diambil kesimpulan dari penelitian ini yaitu semua hipotesis penelitian dapat terbukti. Promosi dan Sadar Wisata Masyarakat signifikan berpengaruh secara langsung maupun tidak langsung terhadap Kepuasan Wisatawan dan Loyalitas Wisatawan untuk loyal dan kembali mengunjungi Pulau Tidung sebagai pilihan rekreasi dan berwisata. Promosi dan sadar wisata masyarakat terhadap loyalitas wisatawan juga menunjukan bahwa sadar wisata masyarakat memiliki pengaruh total lebih besar daripada variabel promosi melalui variabel kepuasan wisatawan sebesar 0.328 .

\section{Saran}

Promosi yang lebih menarik dan intens pada setiap event dan pemilihan waktu yang tepat perlu terus dilakukan oleh pihak pemda maupun masyarakat lokal agar turut meningkatkan keinginan wisatawan baik lokal maupun mancanegara untuk mencoba mengunjungi daerah wisata Kepulauan Seribu khususnya Pulau Tidung. Keamanan, keselamatan dan kenyamanan wisatawan atas sarana dan prasarana wisata perlu menjadi perhatian sebagai bagian dari sadar wisata masyarakat. Pelayanan jasa wisata dan transportasi yang baik menuju destinasi wisata perlu diterapkan pihak pemda dan pihak industri pariwisata. Semua hal tersebut menjadi penting sebagai upaya peningkatan kepuasan para wisatawan atas pengalamannya berwisata ke Pulau Tidung dan berdampak pada loyalitasnya mengunjungi kembali destinasi wisata Pulau Tidung di lain waktu. Penelitian selanjutnya diharapkan lebih baik dalam proses pengumpulan data baik secara primer maupun wawancara pada sumber yang kompeten dengn variabel penelitian yang berbeda.

\section{REFERENSI}

Agus Hermawan. 2012. Komunikasi Pemasaran. Jakarta. Erlangga.

Akpoyomare, B, Ladipo, P, K, A and Rahim, A, G. 2012. The Influence of Product Attributes on Consumer Purchase Decision in the Nigerian Food and Beverages Industry: A Study of Lagos Metropolis. American Journal of Business and Management. I".4. 196-201.

Arikunto, S. 2010. Prosedur Penelitian Suatu Pendekatan Praktik. Jakarta: Rineka Cipta.

Asri Dias Tari. 2019. Pengaruh Kualitas Pelayanan, Promosi dan Harga Terhadap Kepuasan Pengunjung (studi pada pengunjung taman wisata Bukit Sakura). Skripsi. Universitas Lampung.

Daryanto. 2011. Manajemen Pemasaran: Sari Kuliah. Bandung: Satu Nusa.

Efendy Alamsyah Kurnia. 2014. Analisis Pengaruh Kualitas Pelayanan, Harrga, dan Promosi Terhadap Kepuasan Pengunjung di Museum Ronggowarsito Semarang.

Fandy Tjiptono dan Gregorius Chandra. 2016. Service, Quality \& Satisfaction. Yogyakarta. Andi.

Fandy Tjiptono. 2012. Strategi Pemasaran. Edisi 3. Yogyakarta: Andi.

Hariyanto, Oda.I.B. 2017. Membangun Karakter Sadar Wisata Masyarakat di Destinasi Melalui Kearifan Lokal Sunda. Vol 4, No 1, Hal 35. Jurnal Pariwisata. Diakses dari Http://ejournal.bsi.ac.id. Diakses pada 30 Januari 2018 pukul 19:00 WIB.

Hasaruddin. 2017. Pengaruh Kualitas Layanan dan Promosi Terhadap Kepuasan serta Loyalitas Pengunjung Wisata Tanjung Papuma Jember. Juristek, Vol. 5, No. 2, Januari 2017, ISSN 2301-704X. 
Hery Hermawan. 2017. Pengaruh Daya Tarik Wisata, Keselamatan, dan Sarana Wisata Terhadap Kepuasan serta Dampaknya Terhadap Loyalitas Wisatawan (studi community based tourism di Gunung Api Purba). Jurnal Media Wisata, Vol 15, No. 1.

Hurriyanti, Ratih. 2015. Bauran Pemasaran dan Loyalitas Konsumen. Bandung: Alfabeta.

A. J. Muljadi. 2010. Kepariwisataan dan Perjalanan. Jakarta. Penerbit: PT Raja Grafindo Persada.

Kotler, Philip and Gary Armstrong. 2012. Prinsip-prinsip Pemasaran. Edisi 13. Jilid 1. Jakarta: Erlangga.

Kuncoro, Mudrajad. 2010. Dasar-dasar Ekonomika Pembangunan, UPP STIM YKPN Yogyakarta.

Lovelock, C, dan John Wirtz. 2011. Pemasaran Jasa Perspektif edisi 7. Jakarta: Erlangga.

Muhammad, Iqbal, Azhari., Dahlan, Fanami., \& M. Kholik Mawardi. 2015. Pengaruh Customers Experiance Terhadap Kepuasan Pelanggan dan Loyalitas Pelanggan, JUrnal Administrasi Bisnis, Vol.28, No. 1.

Rahim Firmansyah. 2012. Pedoman Kelompok Sadar Wisata. Jakarta: PT Jenderal Pengembangan Destinasi Pariwisata Kementrian Pariwisata dan Ekonomi Kreatif.

Ramadani Diana Octavial. 2017. Pengaruh Promosi, Kualitas, Pelayanan, Harga dan Lokasi Terhadap Kepuasan Pengunjung di Wisata Waterboom Sawahlunto.

Sani, Achmad \& Vivin Maharani. 2013. Metode Penelitian Manajemen Sumber Daya Manusia (Teori, Kuesioner dan Analisis Data). Malang: UIN MALIKI Press. Cetakan Ke-2.

Serdarmayanti. 2014. Sumber Daya Manusia dan Produktivitas Kerja. Jakarta: Mandar Maju. Sugiama, A Gima 2011. Ecotourism Pengembangan Pariwisata Berbasis Konservasi Alam. Guardaya Intimarta. Bandung.

Sugiyono. 2010. Metode Penelitian Penedakatan Kuantitatif, Kualitatif, dan R\&D. Bandung: Alfabeta.

Sugiyono. 2012. Memahami Penelitian Kuantitatif. Bandung: Alfabeta.

Sugiyono. 2013. Metode Penelitian Pendidian Pendeatan Kuantitatif, Kualitatif, dan R\&D. Bandung: Alfabeta.

Sugiyono. 2014. Metode Penelitian Pendidikan Pendekatan Kuantitatif, Kualitatif, dan R\&D. Bandung: Alfabeta.

Sugiyono. 2015. Metode Penelitian Kombinasi (mix Methods). Bandung: Afabeta. 